\title{
Synthetic Biology-Driven Microbial Production of Resveratrol: Advances and Perspectives
}

\author{
Chao Feng ${ }^{1}$, Jing Chen ${ }^{1}$, Wenxin Ye ${ }^{1}$, Kaisen Liao ${ }^{1}$, Zhanshi Wang ${ }^{1}$, Xiaofei Song ${ }^{2,3 \star t}$ and \\ Mingqiang Qiao ${ }^{2,4 * t}$
}

${ }^{1}$ Department of Urology, Tongde Hospital of Zhejiang Province, Hangzhou, China, ${ }^{2}$ The Key Laboratory of Molecular Microbiology and Technology, Ministry of Education, College of Life Sciences, Nankai University, Tianjin, China, ${ }^{3}$ The Key Laboratory of Bioorganic Synthesis of Zhejiang Province, College of Biotechnology and Bioengineering, Zhejiang University of Technology, Hangzhou, China, ${ }^{4}$ College of Life Sciences, Shanxi University, Taiyuan, China

OPEN ACCESS

Edited by:

Shuobo Shi,

Beijing University of Chemical Technology, China

Reviewed by:

Jiazhang Lian,

Zhejiang University, China

Quanli Liu,

Chalmers University of Technology,

Sweden

Yajie Wang,

Westlake University, China

${ }^{*}$ Correspondence:

Xiaofei Song

xiaofei@zjut.edu.cn

Mingqiang Qiao

qiaomq@nankai.edu.cn

${ }^{+}$These authors have contributed equally to this work

Specialty section: This article was submitted to

Synthetic Biology,

a section of the journal Frontiers in Bioengineering and

Biotechnology

Received: 12 December 2021 Accepted: 05 January 2022 Published: 20 January 2022

Citation:

Feng C, Chen J, Ye W, Liao K, Wang Z, Song $X$ and Qiao M (2022) Synthetic Biology-Driven Microbial Production of

Resveratrol: Advances and Perspectives.

Front. Bioeng. Biotechnol. 10:833920. doi: 10.3389/fbioe.2022.833920
Resveratrol, a bioactive natural product found in many plants, is a secondary metabolite and has attracted much attention in the medicine and health care products fields due to its remarkable biological activities including anti-cancer, anti-oxidation, anti-aging, antiinflammation, neuroprotection and anti-glycation. However, traditional chemical synthesis and plant extraction methods are impractical for industrial resveratrol production because of low yield, toxic chemical solvents and environmental pollution during the production process. Recently, the biosynthesis of resveratrol by constructing microbial cell factories has attracted much attention, because it provides a safe and efficient route for the resveratrol production. This review discusses the physiological functions and market applications of resveratrol. In addition, recent significant biotechnology advances in resveratrol biosynthesis are systematically summarized. Furthermore, we discuss the current challenges and future prospects for strain development for large-scale resveratrol production at an industrial level.

Keywords: resveratrol, physiological function, microorganism, metabolic engineering, synthetic biology

\section{INTRODUCTION}

Resveratrol has been universally found in a variety of plants including berries, bilberries, peanuts, grapes and even ferns since it was initially extracted from the root of white hellebore (Veratrum grandiflorum) in 1940 (Lim et al., 2011; Jeandet et al., 2012; Li et al., 2015). In plants, resveratrol, the de novo synthetic phytoalexin, acts as a protector against pathogen invasion and infection (Tian and Liu, 2020). It is known that two isomeric forms exist in nature, including cis- and trans-resveratrol, but the trans isomer is the primary biologically-active form. The anti-tumor properties of resveratrol in multiple human organs or systems, include breast (Sinha et al., 2016), cervical (Liu Q et al., 2020), uterine (Sexton et al., 2006), blood (Breuss et al., 2019), kidney (Den Hartogh and Tsiani, 2019), liver (Jakubczyk et al., 2020), eye (Bola et al., 2014), bladder (Almeida and Silva, 2021), thyroid (Giuliani et al., 2017), esophageal (Zhou et al., 2003), prostate (Zaffaroni and Beretta, 2021), brain (Kiskova et al., 2020), lung (Feng et al., 2016), skin (Ravikumar et al., 2019), gastric (Zulueta et al., 2015), colon (Li et al., 2019), head and neck (Shrotriya et al., 2015), bone (Chen et al., 2019), ovarian (Sirotkin et al., 2020), and cervical (Sun et al., 2021), and have been extensively studied over the last few decades (Baur and Sinclair, 2006). Moreover, as a plant secondary metabolite, resveratrol has also been noted for many pharmacological applications such as an anti-oxidant, anti-inflammatory, anti- 


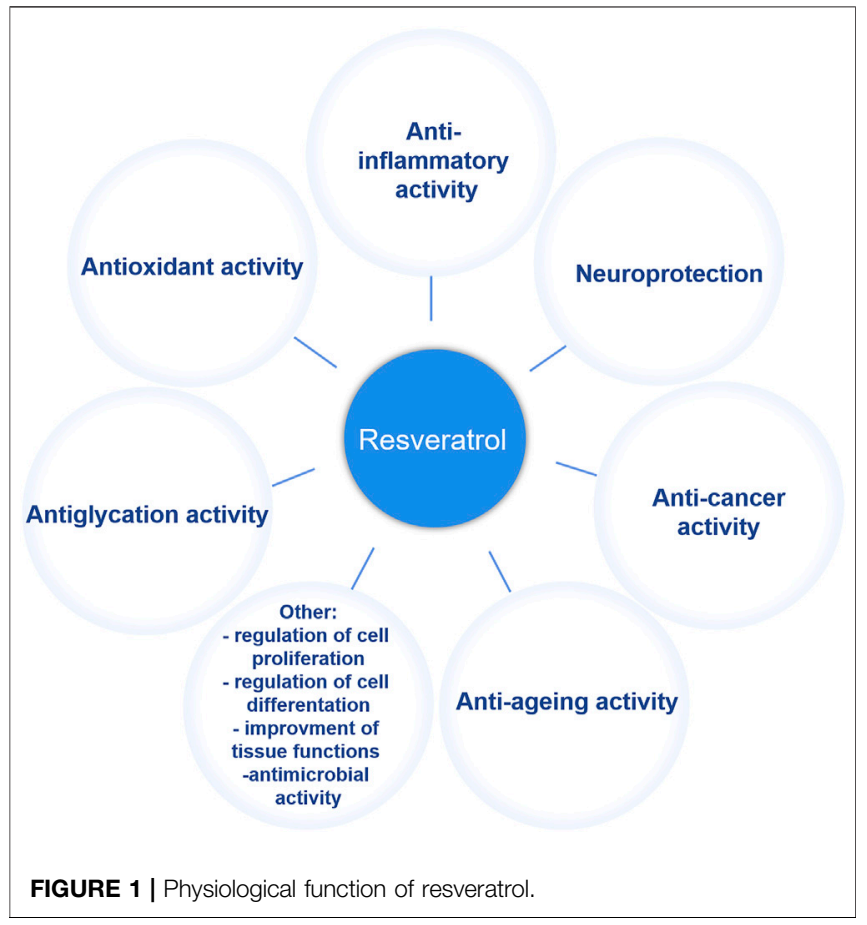

aging, and neuroprotective agent, as well as for many other properties (Rauf et al., 2018) (Figure 1). However, the effects of resveratrol, especially its clinical effects on human health, currently must be further verified and studied because of a limited number of human studies and small cohort sizes. Nevertheless, considering its various physiological activities, resveratrol has attracted much attention in the pharmaceutical, cosmetic and many other industries. Because of an increasing demand in all walks of life, large-scale resveratrol production is urgently needed.

It is difficult to meet the current industry demand for resveratrol by extracting and purifying it from plants, due to the complex process, high production cost and low yield (SáezSáez et al., 2020). Although resveratrol production can currently be increased by employing chemical synthesis, the complex production process, the requirement for toxic solvents and the production of byproducts limits large-scale production (Shrestha et al., 2019). It is noteworthy that the use of microorganisms has made significant contributions to the biosynthesis of pharmaceutical and industrial compounds in recent decades, because of its low production cost, high efficiency, high product purity and simple genetic operation process, and it is considered to have a promising potential for the production of natural products (Cravens et al., 2019). De novo resveratrol biosynthesis via metabolic engineering and synthetic biology in microorganisms provides a feasible way to produce resveratrol, and this has attracted worldwide interest (Liu et al., 2019; He et al., 2020; Liu Z et al., 2020; Yuan et al., 2020; Costa et al., 2021). This review discusses the current status and progress of resveratrol production in recent years, as well as optimization strategies for related hosts, pathways and enzymes for resveratrol production. Hopefully in the next few years, researchers will continue to improve process engineering strategies, and increasingly utilize metabolic and protein engineering to meet a series of more complex biosynthetic challenges.

\section{MICROORGANISM HOSTS FOR RESVERATROL PRODUCTION}

Many properties should be considered when selecting hosts for natural products production. Due to a long history of research, microorganisms have been widely chosen because of mature techniques such as gene editing and large-scale fermentation, particularly for metabolic engineering (Yang et al., 2021). With the increasing demand for resveratrol, many studies have focused on heterologous resveratrol production in prokaryotes such as Escherichia coli, Corynebacterium glutamicum and Streptomyces venezuelae, and in eukaryotes, including Saccharomyces cerevisiae and Yarrowia lipolytica (Dudnik et al., 2018; Cravens et al., 2019). Table 1 presents studies using metabolically engineered strains to produce resveratrol.

\section{YEAST HOSTS}

Yeasts are considered as a more suitable platform than bacteria for the expression of natural products, because of their ability to carry out eukaryotic post-translational modifications and feasibility of genetic manipulation (Madzak, 2015; Braga et al., 2018a). Yeasts and plants have a similar endoplasmic reticulum, an intracellular compartment to support eukaryotic and membrane protein biosynthesis (Rainha et al., 2020). S. cerevisiae is a Generally Regarded As Safe (GRAS) organism that is widely used for pharmaceutical products and food markets because of its safety, and it is more commonly used for resveratrol production than other host species (Fletcher et al., 2016; Pereira et al., 2019). Becker et al. (2003) reconstructed for the first time a biochemical pathway in a microorganism to produce resveratrol and obtained a titer of $0.00145 \mathrm{mg} / \mathrm{L}$ resveratrol in yeast. The biosynthesis of resveratrol via a tyrosine intermediate has been achieved in S. cerevisiae; this was a first time demonstration of the possibility of de novo resveratrol biosynthesis from glucose. By using a pull-push-block strain engineering strategy, $800 \mathrm{mg} / \mathrm{L}$ resveratrol was produced by the engineered host strains ( $\mathrm{Li}$ et al., 2015; Li et al., 2016). Yuan et al. (2020) constructed a consortium system for de novo resveratrol biosynthesis and obtained $36 \mathrm{mg} / \mathrm{L}$ resveratrol. $Y$. lipolytica, another yeast, has been widely concentrated in industrial area for more than 50 years because of its high production capacity for organic acids, which are widely used in diverse research areas (Ma et al., 2020) (Madzak, 2018). $\mathrm{Gu}$ et al. (2020) created resveratrol-producing strains of $Y$. lipolytica, in which could produce $12.67 \pm 2.23 \mathrm{mg} / \mathrm{L}$ of resveratrol with glucose as the substrate. He et al. (2020) engineered Y. lipolytica as a vehicle for high-level resveratrol production and obtained $0.43 \mathrm{~g} / \mathrm{L}$ resveratrol by exploiting the tyrosine and the phenylalanine branches of the pathway. Recently, Sáez-Sáez et al. (2020) tried to improve the resveratrol titer in $Y$. lipolytica by metabolic engineering, 
TABLE 1 | Biosynthesis of resveratrol in engineered microorganisms.

\begin{tabular}{|c|c|c|c|c|c|}
\hline Microbial host & $\begin{array}{l}\text { Pathway genes } \\
\text { (source) }\end{array}$ & $\begin{array}{l}\text { Pathway/Host } \\
\text { engineering }\end{array}$ & Substrate & $\begin{array}{c}\text { Titer } \\
(\mathrm{mg} / \mathrm{L})\end{array}$ & References \\
\hline S. cerevisiae & 4CL1 (A. thaliana) & PAD1 knockout & p-Coumaric & 3.1 & Shin et al. (2011) \\
\hline W303-1A & STS (A. hypogaea) & & acid & & \\
\hline \multirow[t]{3}{*}{ S. cerevisiae WAT11 } & TAL (R. sphaeroides) & Expression of araE transporter (E. coli) & Tyrosine & 3.1 & Wang et al. (2011) \\
\hline & 4CL:STS, 4CL1 (A. thaliana)-STS & & $\begin{array}{l}p \text {-Coumaric } \\
\text { acid }\end{array}$ & 2.3 & \\
\hline & N.vinifera) fusion enzyme & & Grape Juice & 3.44 & \\
\hline S. cerevisiae & PAL (R. toruloides) & Overexpression of ACC1 & Tyrosine & 5.8 & Shin et al. (2012) \\
\hline \multirow[t]{2}{*}{ W303-1A } & C4H, 4CL1 (A. thaliana) & & & & \\
\hline & STS (A. hypogaea) & & & & \\
\hline \multirow[t]{2}{*}{ S. cerevisiae WAT11 } & 4CL1 (A. thaliana) & Synthetic scaffold & p-Coumaric & 14.4 & Wang and Yu, (2012) \\
\hline & STS (V. vinifera) & & acid & & \\
\hline S. cerevisiae WAT11 & $\begin{array}{l}\text { 4CL:STS, 4CL1 (A. thaliana)-STS } \\
\text { N. vinifera) fusion enzyme }\end{array}$ & Overexpression of AAE13 & $\begin{array}{l}p \text {-Coumaric } \\
\text { acid }\end{array}$ & $\begin{array}{c}\text { Up } \\
\text { to } 3.7\end{array}$ & Wang et al. (2014) \\
\hline \multirow{2}{*}{ S. cerevisiae EC1118 } & 4CL (A. thaliana) & - & p-coumaric & 8.249 & Sun et al. (2015) \\
\hline & STS (V. vinifera) & & acid & & \\
\hline \multirow[t]{2}{*}{$\begin{array}{l}\text { S. cerevisiae } \\
\text { CEN.PK102-5B }\end{array}$} & $\begin{array}{l}\text { TAL }(H . \text { aurantiacus) TAL }(F . \\
\text { johnsoniae) 4CL1 and 4CL2 (A. } \\
\text { thaliana) }\end{array}$ & Overexpression of ARO4fbr,ARO7fbr, and ACC1 & $\begin{array}{l}\text { Glucose (Fed- } \\
\text { batch) }\end{array}$ & 415.65 & Li et al. (2015) \\
\hline & RS (V. vinifera) & & $\begin{array}{l}\text { Ethanol (Fed- } \\
\text { batch) }\end{array}$ & 531.41 & \\
\hline \multirow[t]{2}{*}{$\begin{array}{l}\text { S. cerevisiae } \\
\text { CEN.PK102-5B }\end{array}$} & PAL2, C4H, 4CL2 (A. thaliana) & $\begin{array}{l}\text { Overexpression of ARO4fbr, ARO7fbr, ACC1, } \\
\text { CYB5 (S.cerevisiae), ATR2 A. thaliana), ACS (S. }\end{array}$ & $\begin{array}{l}\text { Glucose (Fed- } \\
\text { batch) }\end{array}$ & 812 & Li et al. (2016) \\
\hline & VST1 (V. vinifera) & enterica), and deletion of aro10 & $\begin{array}{l}\text { Ethanol (Fed- } \\
\text { batch) }\end{array}$ & 755 & \\
\hline \multirow[t]{2}{*}{ Y. lipolytica } & 4CL (N. tabacum) & Overexpression of:ACC1, PEX10 & $p$-Coumaric & 48.7 & Palmer et al. (2020) \\
\hline & STS (A. hypogaea) & & acid & & \\
\hline \multirow{4}{*}{$\begin{array}{l}\text { Y. lipolytica Po1d (wt), } \\
\text { derived from W29 }\end{array}$} & TAL (F. johnsoniae) & - & Glycerol & 430 & He et al. (2020) \\
\hline & $\mathrm{PAL}(\mathrm{V}$. vinifera $)$ & & & & \\
\hline & $\mathrm{C} 4 \mathrm{H}, 4 \mathrm{CL} 1$ (A. thaliana) & & & & \\
\hline & VST (V. vinifera) & & & & \\
\hline Y. lipolytica & TAL (F. johnsoniae) & Overexpression of:ARO4fbr and $\mathrm{ARO} 7 \mathrm{fbr}$ & Glucose & 409 & Sáez-Sáez et al. (2020) \\
\hline ST6512 (W29) & $\begin{array}{l}\text { 4CL1 (A. thaliana) VST1 }(V . \\
\text { vinifera) }\end{array}$ & & $\begin{array}{l}\text { Glucose (Fed- } \\
\text { batch) }\end{array}$ & 12,355 & \\
\hline \multirow[t]{2}{*}{$\begin{array}{l}\text { C. glutamicum } \\
\text { DelAro3 }\end{array}$} & STS (A. hypogaea) & Deletion of $p h d B, p c a F$ and $p o b A$ & $\begin{array}{l}p \text {-Coumaric } \\
\text { acid }\end{array}$ & 12 & Kallscheuer et al. (2016) \\
\hline & 4CL (P. crispum) & & $\begin{array}{l}\text { p-coumaric } \\
\text { acid }+ \\
\text { cerulenin }\end{array}$ & 158 & \\
\hline \multirow{6}{*}{$\begin{array}{l}\text { C. glutamicum } \\
\text { DelAro4 }\end{array}$} & TAL (F. johnsoniae) 4CL & Deletion of phdB, pcaF, qsuB and pobA & Glucose & 12 & Braga et al. (2018b) \\
\hline & $\begin{array}{l}\text { (Petroselinum) STS (A. hypogaea) } \\
\text { aroH (E. coli) }\end{array}$ & & $\begin{array}{l}\text { Glucose + } \\
\text { cerulenin }\end{array}$ & 59 & \\
\hline & & & $\begin{array}{l}\text { Glucose } \\
(40 \mathrm{~g} / \mathrm{L})\end{array}$ & 4 & \\
\hline & & & Glucose & 12 & \\
\hline & & & $(80 \mathrm{~g} / \mathrm{L})$ & & \\
\hline & & & $\begin{array}{l}\text { Glucose (Fed- } \\
\text { batch) }\end{array}$ & 7 & \\
\hline \multirow[t]{10}{*}{ E.coli BW27784 } & 4CL (A. thaliana) & - & p-Coumaric & 404 & Lim et al. (2011) \\
\hline & STS (A. hypogaea) & & acid & & \\
\hline & 4CL (A. thaliana) & & & 1,380 & \\
\hline & STS (V. vinifera) & & & & \\
\hline & 4CL (P. crispum) & & & 142 & \\
\hline & STS (A. hypogaea) & & & & \\
\hline & 4CL (P. crispum) & & & 610 & \\
\hline & STS (V. vinífera) & & & & \\
\hline & 4CL (A. thaliana) & & & 2,340 & \\
\hline & STS (V. vinifera) & & & & \\
\hline \multirow[t]{2}{*}{ E. coli C41 (DE3) } & TAL (Saccharothrix espanaensis) & - & p-Coumaric & 1.4 & Choi et al. (2011) \\
\hline & 4CL (Streptomyces coelicolor) & & acid & & \\
\hline \multirow[t]{3}{*}{ E. coli BL21 (DE3) } & TAL (R. glutinis) & - & Tyrosine & 35.02 & Wu et al. (2013) \\
\hline & 4CL (P. crispum) & & & & \\
\hline & $\begin{array}{l}\text { STS }(V . \text { vinifera) matB and matC } \\
(R . \text { trifolii) }\end{array}$ & & & & \\
\hline
\end{tabular}


TABLE 1 | (Continued) Biosynthesis of resveratrol in engineered microorganisms.

\begin{tabular}{|c|c|c|c|c|c|}
\hline Microbial host & $\begin{array}{l}\text { Pathway genes } \\
\text { (source) }\end{array}$ & $\begin{array}{l}\text { Pathway/Host } \\
\text { engineering }\end{array}$ & Substrate & $\begin{array}{l}\text { Titer } \\
\text { (mg/L) }\end{array}$ & References \\
\hline E. coli C41 (DE3) & $\begin{array}{l}\text { TAL (S. espanaensis) } \\
\text { 4-CL (S. coelicolor) } \\
\text { STS (A. hypogaea) }\end{array}$ & - & Glucose & 5.2 & Kang et al. (2014) \\
\hline E. coli BW27784 & $\begin{array}{l}\text { 4CL (A. thaliana) } \\
\text { STS (A. hypogaea) }\end{array}$ & - & $\begin{array}{l}p \text {-Coumaric } \\
\text { acid }\end{array}$ & 160 & Afonso et al. (2015) \\
\hline E. coli BL21 (DE3) & $\begin{array}{l}\text { TAL (S. espanaensis) } \\
\text { 4-CL (A. thaliana) } \\
\text { STS }(A . \text { hypogaea })\end{array}$ & - & Tyrosine & 114.2 & Wang et al. (2015) \\
\hline E. coli BW25113 & $\begin{array}{l}\text { 4CL2 (P.crispum) } \\
\text { STS }(V . \text { vinifera })\end{array}$ & - & $\begin{array}{l}p \text {-Coumaric } \\
\text { acid }\end{array}$ & 268.2 & Yang et al. (2015) \\
\hline $\begin{array}{l}\text { E. coli } \\
\text { BW25113 (DE3) }\end{array}$ & $\begin{array}{l}\text { TAL }(R . \text { glutinis }) \\
\text { 4CL }(P . \text { crispum }) \\
\text { STS }(V . \text { vinifera })\end{array}$ & $\begin{array}{l}\text { Inactivation of tyrR and deletion of trpED by } \\
\text { chromosomal integration }\end{array}$ & Glucose & 4.6 & Liu et al. (2016) \\
\hline $\begin{array}{l}\text { E.coli W (pheA-) Rg } \\
\text { E.coli W-Vv }\end{array}$ & $\begin{array}{l}\text { TAL (R. glutinis) tktAfbr and } \\
\text { aroGfbr (E. coli) } \\
\text { 4CL (S. coelicolor) STS }(V . \text { vinifera) }\end{array}$ & Deletion of pheA & Glycerol & 22.58 & $\begin{array}{l}\text { Camacho-Zaragoza } \\
\text { et al. (2016) }\end{array}$ \\
\hline E. coli BL21 (DE3) & $\begin{array}{l}\text { TAL (Trichosporon cutaneum) } \\
\text { 4CL (P. crispum) } \\
\text { STS (V. vinifera) matB and matC } \\
\text { (R. trifolii) tyrAfbr and aroGfbr } \\
\text { (E.coli K12) }\end{array}$ & Down-regulation of $f a b D, f a b H, f a b B, f a b F, f a b l$ & Glucose & 304.5 & Wu et al. (2017) \\
\hline
\end{tabular}

resulting in $12.4 \pm 0.3 \mathrm{~g} / \mathrm{L}$ resveratrol, which is the highest titer for de novo resveratrol production up to now.

\section{BACTERIAL HOSTS}

E. coli has been the subject of industrial interest for resveratrol production because of its fast growth the availability of advanced technology for its genetic manipulation and synthetic biology (Braga et al., 2018a). Furthermore, tyrosine and p-coumaric acid, the basic precursors of resveratrol, are the critical for increasing production, and are easily assessable and improved in E. coli via multiple metabolic engineering strategies (Shrestha et al., 2019). Additionally, E. coli is more suitable for resveratrol production than yeast because of its high tolerance to p-coumaric acid, another advantage (Shin et al., 2011; Huang et al., 2013) (Donnez et al., 2009). Recently, Zhang et al. identified stilbene synthase as the limiting enzyme via a novel probabilistic computational model and improved the final resveratrol titer from $62.472 \mathrm{mg} / \mathrm{L}$ to $172.799 \mathrm{mg} / \mathrm{L}$, proving the model useful for predicting and improving biological production (Cotner et al., 2021).

Engineered C. glutamicum has also been employed as a vehicle for resveratrol production. Kallscheuer et al. (2016) introduced TAL from Flavobacterium johnsoniae into a strain of C. glutamicum for resveratrol production; $60 \mathrm{mg} / \mathrm{L}$ resveratrol was produced when using glucose as the carbon source. They further achieved $5 \mathrm{mg} / \mathrm{L}$ trans-resveratrol in $C$. glutamicum from 4-hydroxybenzoate, which is the first time a phenylpropanoid was synthesized from 4-hydroxybenzoic acid other than aromatic amino acids and ammonia lyase (Kallscheuer et al., 2017). Milke et al. (2019) constructed a recombinant $C$. glutamicum stain and increased the titer of

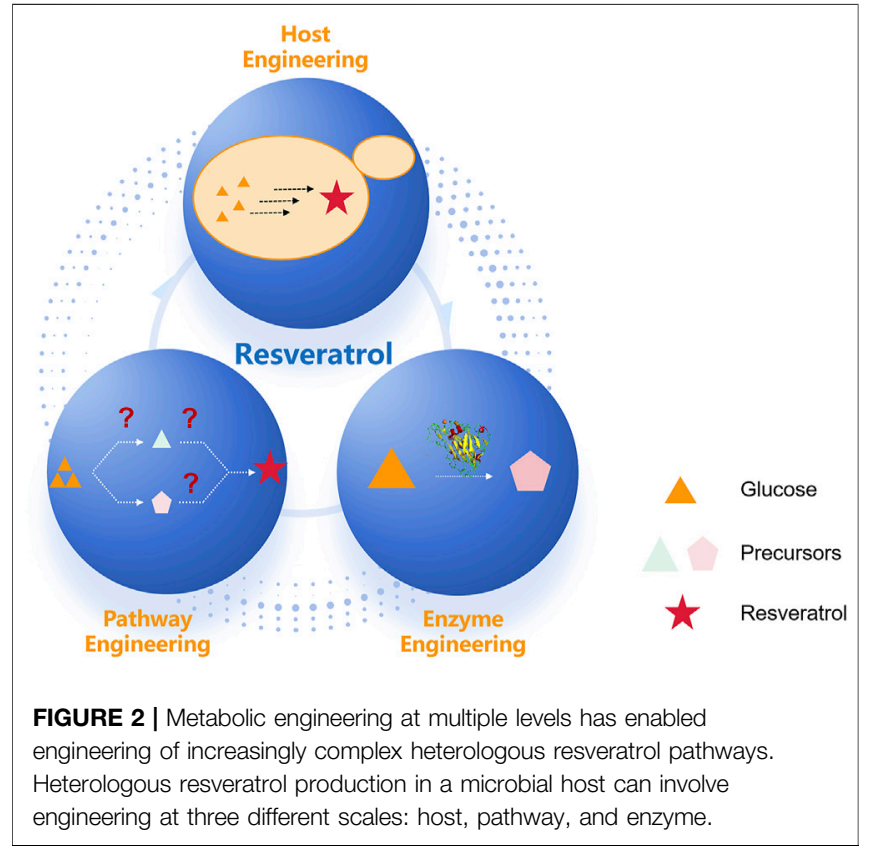

resveratrol to $112 \mathrm{mg} / \mathrm{L}$ by modulating the central carbon metabolism of the host strain.

Engineered S. venezuelae has also been employed to produce resveratrol. Park and others reported resveratrol synthesis by expressing the heterologous phenylpropanoid biosynthetic pathway genes in S. venezuelae for the first time, although they only obtained $0.4 \mathrm{mg} / \mathrm{L}$ of resveratrol (Park et al., 2009). Likewise, the use of other organisms such as Lactobacillus lactis and Aspergillus niger has also been reported for resveratrol bioproduction (Chong et al., 2012). 


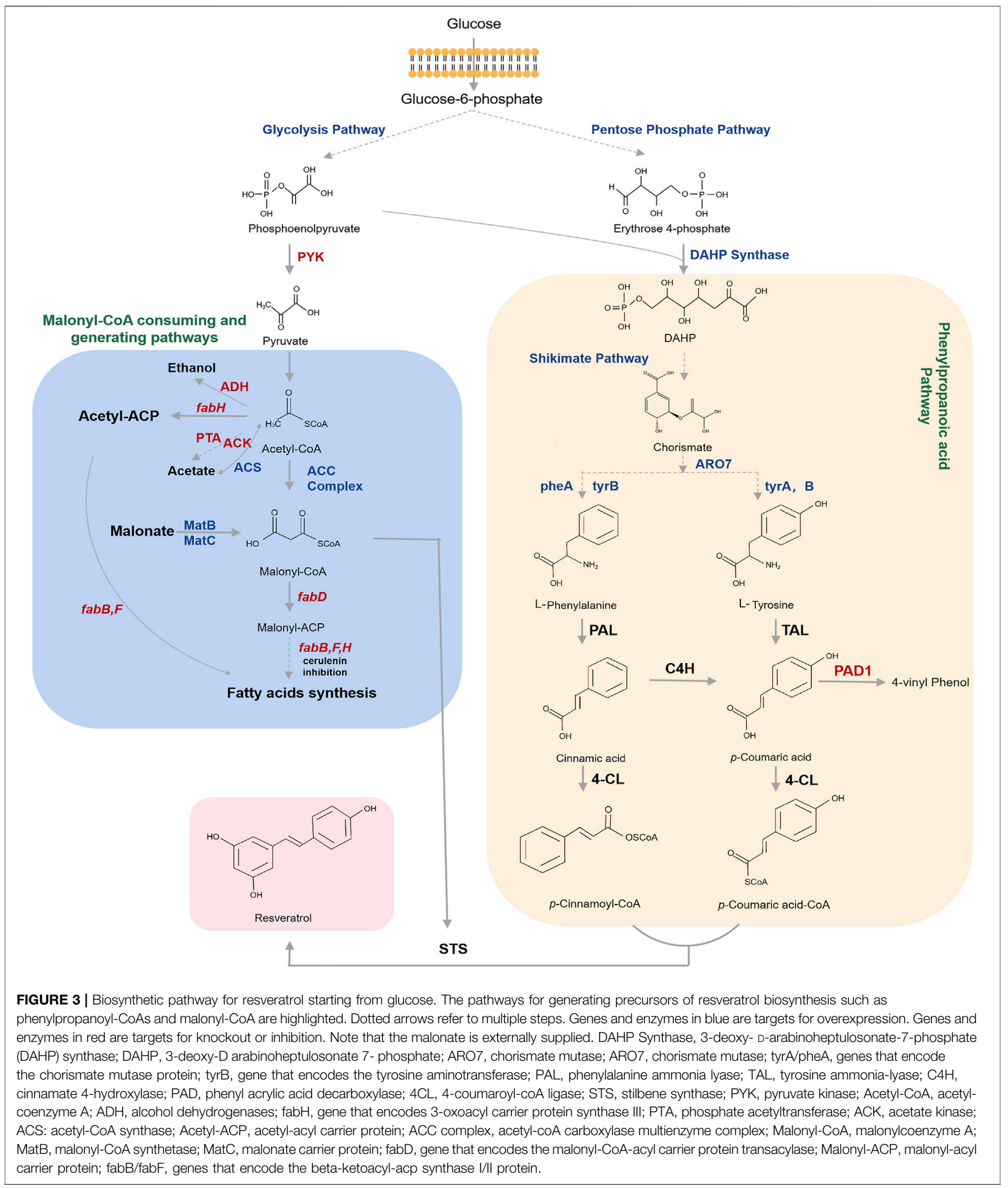




\section{METABOLIC ENGINEERING TO ENHANCE RESVERATROL PRODUCTION}

The design-build-test cycle (DBT cycle) has been widely used in metabolic engineering for the production of plant natural products (Nielsen and Keasling, 2016). In DBT iterative engineering cycles, host engineering includes the sufficient provision of precursor via precursor metabolites overproduction. Pathway engineering includes biosynthesis via a heterologous route to produce natural products, and enzyme engineering includes directed evolution to improve the properties of key rate-limiting enzymes (Cravens et al., 2019) (Figure 2). The rapid development of synthetic biology and enabling technology has accelerated DBT iterative engineering cycles, which have been widely employed for the engineering of resveratrol biosynthesis.

\section{HOST ENGINEERING}

In recent years, significant progress toward high-level resveratrol production has been achieved by microbial metabolic engineering. Nevertheless, an insufficient precursor supply (i.e., aromatic amino acids and malonyl-CoA) is still the main rate-limiting factor for resveratrol production in heterologous hosts. Thus, increasing the precursor supply via genetic manipulation of the host strain is considered a fundamental strategy for resveratrol bioproduction (van SummerenWesenhagen and Marienhagen, 2013; Milke et al., 2018).

As shown in Figure 3, resveratrol is produced from the aromatic amino acids L-phenylalanine (L-Phe) or L-tyrosine (L-Tyr). The metabolic engineering of the shikimic acid pathway primarily regulates the carbon flux into chorismate, followed by L-Phe and L-Tyr (Jiang et al., 2005; Rodriguez et al., 2015). Frequently-used strategies to increase the biosynthetic flux of the shikimic acid pathway are the elimination of enzyme feedback inhibition and the regulation of transcription. Furthermore, extending the supply and availability of erythrose-4-phosphate (E4P) and phosphoenolpyruvate (PEP) are the primary methods for improving chorismate production (Bulter et al., 2003; LütkeEversloh and Stephanopoulos, 2007). Significant strategies have been developed to enhance the production of aromatic amino acids or derived phenylpropanoic acids in microorganisms (Juminaga et al., 2012; Zhang and Stephanopoulos, 2013; Rodriguez et al., 2015). For example, Juminaga et al. (2012) reported the biosynthesis of resveratrol by encoding the key enzymes for converting E4P and PEP to L-Tyr, which significantly increased L-Tyr production to $80 \%$ of the theoretical yield.

Malonyl-CoA also serves as an important precursor for resveratrol biosynthesis. Moreover, malonyl-CoA is mostly used as an essential intermediate for fatty acid biosynthesis to support cell growth, so only a limited level of malonyl-CoA remains for resveratrol biosynthesis, which is a major challenge in resveratrol production. Therefore, two prime strategic steps have been utilized in order to expand the intracellular malonyl-CoA pool in microorganisms: 1) repressing fatty acid biosynthesis to inhibit
malonyl-CoA consumption; 2) expanding the cytoplasmic malonyl-CoA pool by carboxylation of acetyl-CoA carboxylase (ACC), which can increase the amount of acetyl-CoA carboxylation to malonyl-CoA. Zha et al. (2009) found that overexpression of ACC increased the concentration of malonyl$\mathrm{CoA}$ in E. coli. In addition, deleting genes encoding competing pathways, such as pta and ackA, which are involved in the degradation of acetyl-CoA into acetic acid, and the adhE gene, which is involved in ethanol production, can achieve significant effects (Finzel et al., 2015). Yang et al. (2015) revealed that blocking malonyl-CoA consumption and the deletion of the fab genes were lethal in microorganisms. Thus, three procedures have been carried out to inhibit malonyl-CoA consumption: 1) inhibiting FabB and FabF by adding the antibiotic cerulenin (Lim et al., 2011; Lu et al., 2016); 2) using antisense RNA to repress the $f a b$ operon, especially the fabD genes (Wu et al., 2014; Yang et al., 2015); 3) using CRISPRi technology to inhibit the fab gene and direct the carbon flux toward malonyl-CoA (Wu et al., 2015; Liang et al., 2016). Furthermore, another significant approach is to introduce biosynthetic pathway genes for malonate assimilation, such as $m a t B$ and $m a t C$, into the system. (Shin et al., 2011).

\section{PATHWAY ENGINEERING}

By introducing the entire biosynthetic pathway into microorganisms, efficient synthesis of resveratrol from precursors (L-Phe or L-Tyr) or low-cost materials (such as glucose, ethanol or glycerol) can be realized, which is a great help for de novo biosynthesis or biotransformation of resveratrol (Jeandet et al., 2012; Li et al., 2016; Chen et al., 2020). The biosynthetic pathway for resveratrol is shown in Figure 3. The secondary metabolite phenylpropanoid route is the major metabolic pathway for resveratrol biosynthesis ( $\mathrm{Lu}$ et al., 2016). The first step in resveratrol biosynthesis is the production of phenylpropanoic acids (i.e., $p$-coumaric acid and cinnamic acid) through nonoxidative deamination via tyrosine ammonia lyase (TAL) and L-phenylalanine ammonia lyase (PAL), which are then converted to $p$-coumaroyl-CoA and cinnamoyl-CoA by 4 -coumarate-CoA ligase (4CL). Cinnamic acid can also be hydroxylated with the assistance of cinnamic acid-4-hydroxylase $(\mathrm{C} 4 \mathrm{H})$ to form $p$-coumaric acid. Finally, malonyl-CoA is condensed with $p$-coumaroyl-CoA to produce resveratrol, catalyzed by stilbene synthases (STSs) (van Summeren-Wesenhagen and Marienhagen, 2015; Milke et al., 2018). The main objective for the engineering of this pathway is to efficiently convert the aromatic amino acids to phenylpropyl by introducing hyper-active ammonia lyases such as PAL or TAL (Huang et al., 2013; Zhang and Stephanopoulos, 2013), which is a bottleneck in the resveratrol production from glucose (Yang et al., 2015; Kallscheuer et al., 2016). Liu et al. (2016) introduced TAL, $4 \mathrm{CL}$ and STS genes into E. coli strain and obtained $4.6 \mathrm{mg} / \mathrm{L}$ of resveratrol from glucose. Soon after, Wu et al. (2017) applied multiple metabolic engineering approaches to produce resveratrol from glucose in E. coli. However, the low activity of TAL and PAL enzymes is still the main obstacle for introducing the entire de novo pathway into the microorganism. 


\section{ENZYME ENGINEERING}

As mentioned above, in many cases the function of one or a few key enzymes acts as a bottleneck in the overall metabolic fluxes, which are considered as the rate-limiting steps. Microorganisms cannot produce enough targeted product because of enzymes that have limited turnover or poor expression (Song et al., 2017; Song et al., 2018; Lian et al., 2018). Therefore, protein engineering, particularly directed evolution, has become one of the most powerful and widespread tools for engineering improved or novel functions in enzymes (Wu et al., 2013; Wang et al., 2021). Researchers employed protein engineering of $4 \mathrm{CL}$ and STS in $E$. coli for higher and more efficient resveratrol production (Becker et al., 2003; Zhang et al., 2015). Likewise, a yeast host harboring codon-optimized TAL and fused 4CL and STS, which allowed the production of $1.06 \mathrm{mg} / \mathrm{L}$ resveratrol without the use of L-Tyr (Wang et al., 2011). Moreover, the robustness of the rate-limiting enzymes or the metabolic activity of pathways can be optimized in vivo via metabolite-responsive biosensors (Skjoedt et al., 2016). Xiong et al. (2017) selected resveratrol hyper-producers rapidly and efficiently by reapplying the TtgR regulatory protein to a resveratrol-responsive biosensor in E. coli. Compared to the wild type, 4CL variants displayed improved catalytic properties for the production of this aromatic compound.

\section{PRODUCTION PROCESS OPTIMIZATION TO INCREASE RESVERATROL SYNTHESIS}

The balance and optimization of microbial growth and product formation have been identified as essential for increasing resveratrol production. In order to satisfy the world's sustainable demand, researchers have conducted some important studies for largescale industrial production. Braga et al. (2018b) observed that increasing the glucose concentration from $40 \mathrm{~g} / \mathrm{L}$ to $80 \mathrm{~g} / \mathrm{L}$ resulted in a resveratrol titer that increased from $4 \mathrm{mg} / \mathrm{L}$ to $12 \mathrm{mg} / \mathrm{L}$, which demonstrated that proper culture conditions, i.e., substrate concentration, were essential for the resveratrol production in C. glutamicum (Braga et al., 2018b).

In order to optimize and construct recombinant strains, the metabolic burden caused by the competition between natural metabolism and chemical production pathways (including chemical precursors, energy molecules and reduction equivalents) is one of the most important challenges to be urgently faced and resolved. Considering that polyphenols such as resveratrol are produced through complex biosynthetic pathways, the concept of co-culture has gained increasing attention in recent years. Through co-culture, that is, using multiple strains to produce different products or metabolize different substrates, it is feasible to co-produce resveratrol. Furthermore, the entire pathway can be divided and introduced into each strain as an entire module (Zhou et al., 2015). Yuan et al. (2020) recently described an approach utilizing a co-culture of E. coli-S. cerevisiae to produce resveratrol, with a final titer of $36 \mathrm{mg} / \mathrm{L}$ using glucose as a carbon source. To alleviate the metabolic burden of a single host, researchers divided the labor among artificial microbial communities using a cell consortium strategy (Yuan et al., 2020).
There are many other obstacles to resveratrol production in microbial hosts, such as the high cost of precursors and precursor toxicity. Researchers recently attempted to overcome these difficulties by using engineered strains to obtain low-cost and sustainable substrates and by using fed-batch cultures to reduce the toxicity of precursors (Wu et al., 2017) (Watts et al., 2006; Huang et al., 2013; Zhang and Stephanopoulos, 2013).

\section{CONCLUSION AND FUTURE PERSPECTIVES}

As of now, the efforts and results mentioned above have demonstrated the feasibility of converting microorganism hosts into cell factories to produce resveratrol, which can be achieved by grafting exogenous biosynthetic pathways into the endogenous metabolic network of cells. However, the current problem is that although they have promising potential for development and popularization, at present the performance of most engineered strains cannot achieve the goals required for industrial production. How to use microorganisms as vehicles to produce resveratrol more economically is still an important challenge. Multiple factors, including the cytotoxicity of end products, the low activity and stability of catalytic enzymes, and metabolic imbalances at the biosynthetic pathway level and across the cellular network, are challenges for the advancement of cell growth, the rate of production, product titer and yield to a certain degree. Furthermore, the production process is also hampered by the lack of critical, basic information about the interactions and regulation of metabolic networks, which require more time to discover and verify the contribution of potential biosynthetic pathways for resveratrol production. However, with the recent rapid development of metabolic engineering principles, it is expected that novel and reliable solutions will be found that will break the shackles that hinder industrial biological resveratrol production.

The cellular adaptation and metabolic stability of engineered cell factories has frequently been affected by heterologous chemicals, which are tremendously cytotoxic during the process of biosynthesis and long-term accumulation. Consequently, some approaches, including adaptive laboratory evolution (ALE) (Sandberg et al., 2019) and the multi-functional genome-wide CRISPR (MAGIC) system (Lian et al., 2019), have been designed to reduce the toxicity of products while maximizing the potency and yield of chemical products. For instance, Pereira et al. (2019) recently investigated through ALE experiments the mechanism of tolerance of $S$. cerevisiae to the cellular stress imposed by inhibiting concentrations of dicarboxylic acids. Lian et al. (2019) improved furfural tolerance in yeast using the MAGIC system; a method that identifies complex phenotypic genetic determinants that have not been previously identified, especially those interacting synergistically when disturbed to different levels of expression. The novel strategies mentioned above represent a promising alternative strategy to improve the resveratrol production capability of microbial hosts.

In order to alleviate the rate-limiting steps, protein engineering, especially directed evolution, has been applied to improve enzyme properties. It is particularly worth noting that machine learning has been increasingly utilized for protein engineering. Luo et al. 
developed a high-performance method called Evolutionary ContextIntegrated Neural Network (ECNet), providing generalization from low-order mutants to higher-order mutants, which can predict protein function levels from sequence to protein engineering process (Luo et al., 2021). Besides, recent advances in the development of sequence-based, MD-based, structure-based, and machine learning-based computational tools will promote the identification of the beneficial mutations and accelerate the protein engineering process by creating smaller but smarter libraries to enhance the robustness of catalytic enzymes (Huang et al., 2016). Moreover, attention should be paid to a combinatorial method to guide every precursor and metabolite towards the largescale resveratrol production. Additionally, for resveratrol biosynthesis processes based on a microbial platform, the application of complete biosynthetic and related knowledge of molecular biology, including the entire genome, transcriptome, proteome and metabolome, will be promising for the improvement of the production efficiency and yield of resveratrol.

In summary, the goal of efficient resveratrol production in microbial hosts can be advanced by the integration of multiple

\section{REFERENCES}

Afonso, M. S., Ferreira, S., Domingues, F. C., and Silva, F. (2015). Resveratrol Production in Bioreactor: Assessment of Cell Physiological States and Plasmid Segregational Stability. Biotechnol. Rep. 5, 7-13. doi:10.1016/j.btre.2014.10.008

Almeida, T. C., and Silva, G. N. d. (2021). Resveratrol Effects in Bladder Cancer: A Mini Review. Genet. Mol. Biol. 44, e20200371. doi:10.1590/1678-4685-GMB-2020-0371

Baur, J. A., and Sinclair, D. A. (2006). Therapeutic Potential of Resveratrol: the In Vivo Evidence. Nat. Rev. Drug Discov. 5, 493-506. doi:10.1038/nrd2060

Becker, J., Armstrong, G., Vandermerwe, M., Lambrechts, M., Vivier, M., and Pretorius, I. (2003). Metabolic Engineering of for the Synthesis of the Wine-Related Antioxidant Resveratrol. FEMS Yeast Res. 4 (1), 79-85. doi:10.1016/s1567-1356(03)00157-0

Bola, C., Bartlett, H., and Eperjesi, F. (2014). Resveratrol and the Eye: Activity and Molecular Mechanisms. Graefes Arch. Clin. Exp. Ophthalmol. 252, 699-713. doi:10.1007/s00417-014-2604-8

Braga, A., Ferreira, P., Oliveira, J., Rocha, I., and Faria, N. (2018a). Heterologous Production of Resveratrol in Bacterial Hosts: Current Status and Perspectives. World J. Microbiol. Biotechnol. 34, 122. doi:10.1007/s11274-018-2506-8

Braga, A., Oliveira, J., Silva, R., Ferreira, P., Rocha, I., Kallscheuer, N., et al. (2018b). Impact of the Cultivation Strategy on Resveratrol Production from Glucose in Engineered Corynebacterium Glutamicum. J. Biotechnol. 265, 70-75. doi:10.1016/j.jbiotec.2017.11.006

Breuss, J., Atanasov, A., and Uhrin, P. (2019). Resveratrol and its Effects on the Vascular System. Ijms 20, 1523. doi:10.3390/ijms20071523

Bulter, T., Bernstein, J. R., and Liao, J. C. (2003). A Perspective of Metabolic Engineering Strategies: Moving up the Systems Hierarchy. Biotechnol. Bioeng. 84, 815-821. doi:10.1002/bit.10845

Camacho-Zaragoza, J. M., Hernández-Chávez, G., Moreno-Avitia, F., RamírezIñiguez, R., Martínez, A., Bolívar, F., et al. (2016). Engineering of a Microbial Coculture of Escherichia coli Strains for the Biosynthesis of Resveratrol. Microb. Cel Fact 15, 163. doi:10.1186/s12934-016-0562-Z

Chen, G., Xia, H., Zhang, Z.-g., and Yu, H.-l. (2019). Resveratrol in Management of Bone and Spinal Cancers. Nat. Prod. Res. 33, 516-526. doi:10.1080/ 14786419.2017.1389936

Chen, R., Yang, S., Zhang, L., and Zhou, Y. J. (2020). Advanced Strategies for Production of Natural Products in Yeast. iScience 23, 100879. doi:10.1016/ j.isci.2020.100879

Choi, O., Wu, C.-Z., Kang, S. Y., Ahn, J. S., Uhm, T.-B., and Hong, Y.-S. (2011). Biosynthesis of Plant-specific Phenylpropanoids by Construction of an Artificial Biosynthetic Pathway in Escherichia coli. J. Ind. Microbiol. Biotechnol. 38, 1657-1665. doi:10.1007/s10295-011-0954-3 tools such as metabolic engineering, systems and synthetic biology for strain design, as well as by improving process engineering strategies. By using such strategies, heterologous resveratrol production can be competitive with existing chemical synthesis and plant extraction processes, which will be a better choice to achieve the goal of sustainable resveratrol production.

\section{AUTHOR CONTRIBUTIONS}

CF wrote the manuscript. JC, WY, KL, and ZW searched the literatures. XS and MQ designed the review. All authors revised and approved the manuscript.

\section{ACKNOWLEDGMENTS}

We thank Ligang Ren (Department of Urology, Tongde Hospital of Zhejiang province, Hangzhou, Zhejiang, P.R.China) for his support and encouragement.

Chong, Y., Yan, A., Yang, X., Cai, Y., and Chen, J. (2012). An Optimum Fermentation Model Established by Genetic Algorithm for Biotransformation from Crude Polydatin to Resveratrol. Appl. Biochem. Biotechnol. 166, 446-457. doi:10.1007/s12010-011-9440-7

Costa, C. E., Møller-Hansen, I., Romaní, A., Teixeira, J. A., Borodina, I., and Domingues, L. (2021). Resveratrol Production from Hydrothermally Pretreated Eucalyptus Wood Using Recombinant Industrial Saccharomyces cerevisiae Strains. ACS Synth. Biol. 10, 1895-1903. doi:10.1021/acssynbio.1c00120

Cotner, M., Zhan, J., and Zhang, Z. (2021). A Computational Metabolic Model for Engineered Production of Resveratrol in Escherichia coli. ACS Synth. Biol. 10, 1992-2001. doi:10.1021/acssynbio.1c00163

Cravens, A., Payne, J., and Smolke, C. D. (2019). Synthetic Biology Strategies for Microbial Biosynthesis of Plant Natural Products. Nat. Commun. 10, 2142. doi:10.1038/s41467-019-09848-w

Den Hartogh, D. J., and Tsiani, E. (2019). Health Benefits of Resveratrol in Kidney Disease: Evidence from In Vitro and In Vivo Studies. Nutrients 11, 1624. doi:10.3390/nu11071624

Donnez, D., Jeandet, P., Clément, C., and Courot, E. (2009). Bioproduction of Resveratrol and Stilbene Derivatives by Plant Cells and Microorganisms. Trends Biotechnology 27, 706-713. doi:10.1016/j.tibtech.2009.09.005

Dudnik, A., Gaspar, P., Neves, A. R., and Forster, J. (2018). Engineering of Microbial Cell Factories for the Production of Plant Polyphenols with Health-Beneficial Properties. Cpd 24, 2208-2225. doi:10.2174/1381612824666180515152049

Feng, Y., Zhou, J., and Jiang, Y. (2016). Resveratrol in Lung Cancer- a Systematic Review. J. BUON 21, 950-953.

Finzel, K., Lee, D. J., and Burkart, M. D. (2015). Using Modern Tools to Probe the Structure-Function Relationship of Fatty Acid Synthases. ChemBioChem 16, 528-547. doi:10.1002/cbic.201402578

Fletcher, E., Krivoruchko, A., and Nielsen, J. (2016). Industrial Systems Biology and its Impact on Synthetic Biology of Yeast Cell Factories. Biotechnol. Bioeng. 113, 1164-1170. doi:10.1002/bit.25870

Giuliani, C., Iezzi, M., Ciolli, L., Hysi, A., Bucci, I., Di Santo, S., et al. (2017). Resveratrol Has Anti-thyroid Effects Both In Vitro and In Vivo. Food Chem. Toxicol. 107, 237-247. doi:10.1016/j.fct.2017.06.044

Gu, Y., Ma, J., Zhu, Y., Ding, X., and Xu, P. (2020). Engineering Yarrowia Lipolytica as a Chassis for De Novo Synthesis of Five Aromatic-Derived Natural Products and Chemicals. ACS Synth. Biol. 9, 2096-2106. doi:10.1021/acssynbio.0c00185

He, Q., Szczepańska, P., Yuzbashev, T., Lazar, Z., and Ledesma-Amaro, R. (2020). De Novo production of Resveratrol from Glycerol by Engineering Different Metabolic Pathways in Yarrowia Lipolytica. Metab. Eng. Commun. 11, e00146. doi:10.1016/j.mec.2020.e00146 
Huang, P.-S., Boyken, S. E., and Baker, D. (2016). The Coming of Age of De Novo Protein Design. Nature 537, 320-327. doi:10.1038/nature19946

Huang, Q., Lin, Y., and Yan, Y. (2013). Caffeic Acid Production Enhancement by Engineering a Phenylalanine Over-producingEscherichia Colistrain. Biotechnol. Bioeng. 110, 3188-3196. doi:10.1002/bit.24988

Jakubczyk, K., Skonieczna-Żydecka, K., Kałduńska, J., Stachowska, E., Gutowska, I., and Janda, K. (2020). Effects of Resveratrol Supplementation in Patients with Non-Alcoholic Fatty Liver Disease-A Meta-Analysis. Nutrients 12, 2435. doi: $10.3390 /$ nu12082435

Jeandet, P., Delaunois, B., Aziz, A., Donnez, D., Vasserot, Y., Cordelier, S., et al. (2012). Metabolic Engineering of Yeast and Plants for the Production of the Biologically Active Hydroxystilbene, Resveratrol. J. Biomed. Biotechnol. 2012, 1-14. doi:10.1155/2012/579089

Jiang, H., Wood, K. V., and Morgan, J. A. (2005). Metabolic Engineering of the Phenylpropanoid Pathway in Saccharomyces cerevisiae. Appl. Environ. Microbiol. 71, 2962-2969. doi:10.1128/AEM.71.6.2962-2969.2005

Juminaga, D., Baidoo, E. E. K., Redding-Johanson, A. M., Batth, T. S., Burd, H., Mukhopadhyay, A., et al. (2012). Modular Engineering of L-Tyrosine Production in Escherichia coli. Appl. Environ. Microbiol. 78, 89-98. doi:10.1128/AEM.06017-11

Kallscheuer, N., Vogt, M., and Marienhagen, J. (2017). A Novel Synthetic Pathway Enables Microbial Production of Polyphenols Independent from the Endogenous Aromatic Amino Acid Metabolism. ACS Synth. Biol. 6, 410-415. doi:10.1021/acssynbio.6b00291

Kallscheuer, N., Vogt, M., Stenzel, A., Gätgens, J., Bott, M., and Marienhagen, J. (2016). Construction of a Corynebacterium Glutamicum Platform Strain for the Production of Stilbenes and (2S)-Flavanones. Metab. Eng. 38, 47-55. doi:10.1016/j.ymben.2016.06.003

Kang, S.-Y., Lee, J. K., Choi, O., Kim, C. Y., Jang, J.-H., Hwang, B. Y., et al. (2014). Biosynthesis of Methylated Resveratrol Analogs through the Construction of an Artificial Biosynthetic Pathway in E. coli. BMC Biotechnol. 14, 67. doi:10.1186/ $1472-6750-14-67$

Kiskova, T., Kubatka, P., Büsselberg, D., and Kassayova, M. (2020). The PlantDerived Compound Resveratrol in Brain Cancer: A Review. Biomolecules 10, 161. doi:10.3390/biom10010161

Li, D., Wang, G., Jin, G., Yao, K., Zhao, Z., Bie, L., et al. (2019). Resveratrol Suppresses colon Cancer Growth by Targeting the AKT/STAT3 Signaling Pathway. Int. J. Mol. Med. 43, 630-640. doi:10.3892/ijmm.2018.3969

Li, M., Kildegaard, K. R., Chen, Y., Rodriguez, A., Borodina, I., and Nielsen, J. (2015). De Novo production of Resveratrol from Glucose or Ethanol by Engineered Saccharomyces cerevisiae. Metab. Eng. 32, 1-11. doi:10.1016/j.ymben.2015.08.007

Li, M., Schneider, K., Kristensen, M., Borodina, I., and Nielsen, J. (2016). Engineering Yeast for High-Level Production of Stilbenoid Antioxidants. Sci. Rep. 6, 36827. doi:10.1038/srep36827

Lian, J., Mishra, S., and Zhao, H. (2018). Recent Advances in Metabolic Engineering of Saccharomyces cerevisiae: New Tools and Their Applications. Metab. Eng. 50, 85-108. doi:10.1016/j.ymben.2018.04.011

Lian, J., Schultz, C., Cao, M., HamediRad, M., and Zhao, H. (2019). Multifunctional Genome-wide CRISPR System for High Throughput GenotypePhenotype Mapping. Nat. Commun. 10, 5794. doi:10.1038/s41467-019-13621-4

Liang, J.-1., Guo, L.-q., Lin, J.-f., He, Z.-q., Cai, F.-j., and Chen, J.-f. (2016). A Novel Process for Obtaining Pinosylvin Using Combinatorial Bioengineering in Escherichia coli. World J. Microbiol. Biotechnol. 32, 102. doi:10.1007/s11274-016-2062-z

Lim, C. G., Fowler, Z. L., Hueller, T., Schaffer, S., and Koffas, M. A. G. (2011). Highyield Resveratrol Production in Engineered Escherichia coli. Appl. Environ. Microbiol. 77, 3451-3460. doi:10.1128/AEM.02186-10

Liu, Q., Liu, Y., Chen, Y., and Nielsen, J. (2020). Current State of Aromatics Production Using Yeast: Achievements and Challenges. Curr. Opin. Biotechnol. 65, 65-74. doi:10.1016/j.copbio.2020.01.008

Liu, Q., Yu, T., Li, X., Chen, Y., Campbell, K., Nielsen, J., et al. (2019). Rewiring Carbon Metabolism in Yeast for High Level Production of Aromatic Chemicals. Nat. Commun. 10, 4976. doi:10.1038/s41467-019-12961-5

Liu, X., Lin, J., Hu, H., Zhou, B., and Zhu, B. (2016). De Novobiosynthesis of Resveratrol by Site-specific Integration of Heterologous Genes inEscherichia Coli. FEMS Microbiol. Lett. 363, fnw061. doi:10.1093/femsle/fnw061

Liu, Z., Li, Y., She, G., Zheng, X., Shao, L., Wang, P., et al. (2020). Resveratrol Induces Cervical Cancer HeLa Cell Apoptosis through the Activation and Nuclear Translocation Promotion of FOXO3a. Pharmazie 75, 250-254. doi:10.1691/ph.2020.0386
Lu, Y., Shao, D., Shi, J., Huang, Q., Yang, H., and Jin, M. (2016). Strategies for Enhancing Resveratrol Production and the Expression of Pathway Enzymes. Appl. Microbiol. Biotechnol. 100, 7407-7421. doi:10.1007/s00253-016-7723-1

Luo, Y., Jiang, G., Yu, T., Liu, Y., Vo, L., Ding, H., et al. (2021). ECNet Is an Evolutionary Context-Integrated Deep Learning Framework for Protein Engineering. Nat. Commun. 12, 5743. doi:10.1038/s41467-021-25976-8

Lütke-Eversloh, T., and Stephanopoulos, G. (2007). L-tyrosine Production by Deregulated Strains of Escherichia coli. Appl. Microbiol. Biotechnol. 75, 103-110. doi:10.1007/s00253-006-0792-9

Ma, J., Gu, Y., Marsafari, M., and Xu, P. (2020). Synthetic Biology, Systems Biology, and Metabolic Engineering of Yarrowia Lipolytica toward a Sustainable Biorefinery Platform. J. Ind. Microbiol. Biotechnol. 47, 845-862. doi:10.1007/ s10295-020-02290-8

Madzak, C. (2018). Engineering Yarrowia Lipolytica for Use in Biotechnological Applications: A Review of Major Achievements and Recent Innovations. Mol. Biotechnol. 60, 621-635. doi:10.1007/s12033-018-0093-4

Madzak, C. (2015). Yarrowia Lipolytica: Recent Achievements in Heterologous Protein Expression and Pathway Engineering. Appl. Microbiol. Biotechnol. 99, 4559-4577. doi:10.1007/s00253-015-6624-z

Milke, L., Aschenbrenner, J., Marienhagen, J., and Kallscheuer, N. (2018). Production of Plant-Derived Polyphenols in Microorganisms: Current State and Perspectives. Appl. Microbiol. Biotechnol. 102, 1575-1585. doi:10.1007/ s00253-018-8747-5

Milke, L., Ferreira, P., Kallscheuer, N., Braga, A., Vogt, M., Kappelmann, J., et al. (2019). Modulation of the central Carbon Metabolism of Corynebacterium Glutamicum Improves malonyl-CoA Availability and Increases Plant Polyphenol Synthesis. Biotechnol. Bioeng. 116, 1380-1391. doi:10.1002/ bit.26939

Nielsen, J., and Keasling, J. D. (2016). Engineering Cellular Metabolism. Cell 164, 1185-1197. doi:10.1016/j.cell.2016.02.004

Palmer, C. M., Miller, K. K., Nguyen, A., and Alper, H. S. (2020). Engineering 4Coumaroyl-CoA Derived Polyketide Production in Yarrowia Lipolytica through a $\beta$-oxidation Mediated Strategy. Metab. Eng. 57, 174-181. doi:10.1016/j.ymben.2019.11.006

Park, S. R., Yoon, J. A., Paik, J. H., Park, J. W., Jung, W. S., Ban, Y.-H., et al. (2009). Engineering of Plant-specific Phenylpropanoids Biosynthesis in Streptomyces Venezuelae. J. Biotechnol. 141, 181-188. doi:10.1016/j.jbiotec.2009.03.013

Pereira, R., Wei, Y., Mohamed, E., Radi, M., Malina, C., Herrgård, M. J., et al. (2019). Adaptive Laboratory Evolution of Tolerance to Dicarboxylic Acids in Saccharomyces cerevisiae. Metab. Eng. 56, 130-141. doi:10.1016/ j.ymben.2019.09.008

Rainha, J., Gomes, D., Rodrigues, L. R., and Rodrigues, J. L. (2020). Synthetic Biology Approaches to Engineer Saccharomyces cerevisiae towards the Industrial Production of Valuable Polyphenolic Compounds. Life 10, 56. doi:10.3390/life10050056

Rauf, A., Imran, M., Butt, M. S., Nadeem, M., Peters, D. G., and Mubarak, M. S. (2018). Resveratrol as an Anti-cancer Agent: A Review. Crit. Rev. Food Sci. Nutr. 58, 1428-1447. doi:10.1080/10408398.2016.1263597

Ravikumar, P., Katariya, M., Patil, S., Tatke, P., and Pillai, R. (2019). Skin Delivery of Resveratrol Encapsulated Lipidic Formulation for Melanoma Chemoprevention. J. microencapsulation 36, 1-17. doi:10.1080/ 02652048.2019.1649481

Rodriguez, A., Kildegaard, K. R., Li, M., Borodina, I., and Nielsen, J. (2015). Establishment of a Yeast Platform Strain for Production of $P$-Coumaric Acid through Metabolic Engineering of Aromatic Amino Acid Biosynthesis. Metab. Eng. 31, 181-188. doi:10.1016/j.ymben.2015.08.003

Sáez-Sáez, J., Wang, G., Marella, E. R., Sudarsan, S., Cernuda Pastor, M., and Borodina, I. (2020). Engineering the Oleaginous Yeast Yarrowia Lipolytica for High-Level Resveratrol Production. Metab. Eng. 62, 51-61. doi:10.1016/ j.ymben.2020.08.009

Sandberg, T. E., Salazar, M. J., Weng, L. L., Palsson, B. O., and Feist, A. M. (2019). The Emergence of Adaptive Laboratory Evolution as an Efficient Tool for Biological Discovery and Industrial Biotechnology. Metab. Eng. 56, 1-16. doi:10.1016/j.ymben.2019.08.004

Sexton, É., Van Themsche, C., LeBlanc, K., Parent, S., Lemoine, P., and Asselin, E. (2006). Resveratrol Interferes with AKT Activity and Triggers Apoptosis in Human Uterine Cancer Cells. Mol. Cancer 5, 45. doi:10.1186/ 1476-4598-5-45 
Shin, S.-Y., Han, N. S., Park, Y.-C., Kim, M.-D., and Seo, J.-H. (2011). Production of Resveratrol from P-Coumaric Acid in Recombinant Saccharomyces cerevisiae Expressing 4-coumarate:coenzyme A Ligase and Stilbene Synthase Genes. Enzyme Microb. Technol. 48, 48-53. doi:10.1016/j.enzmictec.2010.09.004

Shin, S.-Y., Jung, S.-M., Kim, M.-D., Han, N. S., and Seo, J.-H. (2012). Production of Resveratrol from Tyrosine in Metabolically Engineered Saccharomyces cerevisiae. Enzyme Microb. Technol. 51, 211-216. doi:10.1016/ j.enzmictec.2012.06.005

Shrestha, A., Pandey, R. P., and Sohng, J. K. (2019). Biosynthesis of Resveratrol and Piceatannol in Engineered Microbial Strains: Achievements and Perspectives. Appl. Microbiol. Biotechnol. 103, 2959-2972. doi:10.1007/s00253-019-09672-8

Shrotriya, S., Agarwal, R., and Sclafani, R. A. (2015). A Perspective on Chemoprevention by Resveratrol in Head and Neck Squamous Cell Carcinoma. Adv. Exp. Med. Biol. 815, 333-348. doi:10.1007/978-3-319-09614-8_19

Sinha, D., Sarkar, N., Biswas, J., and Bishayee, A. (2016). Resveratrol for Breast Cancer Prevention and Therapy: Preclinical Evidence and Molecular Mechanisms. Semin. Cancer Biol. 40-41, 209-232. doi:10.1016/j.semcancer.2015.11.001

Sirotkin, A., Kádasi, A., Balaží, A., Kotwica, J., Alwasel, S., and Harrath, A. H. (2020). The Action of Benzene, Resveratrol and Their Combination on Ovarian Cell Hormone Release. Folia Biol. (Praha) 66, 67-71.

Skjoedt, M. L., Snoek, T., Kildegaard, K. R., Arsovska, D., Eichenberger, M., Goedecke, T. J., et al. (2016). Engineering Prokaryotic Transcriptional Activators as Metabolite Biosensors in Yeast. Nat. Chem. Biol. 12, 951-958. doi:10.1038/nchembio.2177

Song, X., Li, Y., Wu, Y., Cai, M., Liu, Q., Gao, K., et al. (2018). Metabolic Engineering Strategies for Improvement of Ethanol Production in Cellulolytic Saccharomyces cerevisiae. FEMS yeast Res. 18 (8), foy090. doi:10.1093/femsyr/foy090

Song, X., Liu, Q., Mao, J., Wu, Y., Li, Y., Gao, K., et al. (2017). POT1-mediated $\delta$ integration Strategy for High-Copy, Stable Expression of Heterologous Proteins in Saccharomyces cerevisiae. FEMS yeast Res. 17 (6), fox064. doi:10.1093/ femsyr/fox064

Sun, P., Liang, J.-L., Kang, L.-Z., Huang, X.-Y., Huang, J.-J., Ye, Z.-W., et al. (2015). Increased Resveratrol Production in Wines Using Engineered Wine strainsSaccharomyces cerevisiaeEC1118 and Relaxed Antibiotic or Auxotrophic Selection. Biotechnol. Prog. 31, 650-655. doi:10.1002/btpr.2057

Sun, X., Fu, P., Xie, L., Chai, S., Xu, Q., Zeng, L., et al. (2021). Resveratrol Inhibits the Progression of Cervical Cancer by Suppressing the Transcription and Expression of HPV E6 and E7 Genes. Int. J. Mol. Med. 47, 335-345. doi:10.3892/ijmm.2020.4789

Tian, B., and Liu, J. (2020). Resveratrol: a Review of Plant Sources, Synthesis, Stability, Modification and Food Application. J. Sci. Food Agric. 100, 1392-1404. doi:10.1002/jsfa.10152

van Summeren-Wesenhagen, P. V., and Marienhagen, J. (2015). Metabolic Engineering of Escherichia coli for the Synthesis of the Plant Polyphenol Pinosylvin. Appl. Environ. Microbiol. 81, 840-849. doi:10.1128/AEM.02966-14

van Summeren-Wesenhagen, P. V., and Marienhagen, J. (2013). Putting Bugs to the Blush. Bioengineered 4, 355-362. doi:10.4161/bioe.23885

Wang, S., Zhang, S., Xiao, A., Rasmussen, M., Skidmore, C., and Zhan, J. (2015). Metabolic Engineering of Escherichia coli for the Biosynthesis of Various Phenylpropanoid Derivatives. Metab. Eng. 29, 153-159. doi:10.1016/ j.ymben.2015.03.011

Wang, Y., Chen, H., and Yu, O. (2014). A Plant Malonyl-CoA Synthetase Enhances Lipid Content and Polyketide Yield in Yeast Cells. Appl. Microbiol. Biotechnol. 98, 5435-5447. doi:10.1007/s00253-014-5612-Z

Wang, Y., Halls, C., Zhang, J., Matsuno, M., Zhang, Y., and Yu, O. (2011). Stepwise Increase of Resveratrol Biosynthesis in Yeast Saccharomyces cerevisiae by Metabolic Engineering. Metab. Eng. 13, 455-463. doi:10.1016/ j.ymben.2011.04.005

Wang, Y., Xue, P., Cao, M., Yu, T., Lane, S. T., and Zhao, H. (2021). Directed Evolution: Methodologies and Applications. Chem. Rev. 121, 12384-12444. doi:10.1021/acs.chemrev.1c00260

Wang, Y., and Yu, O. (2012). Synthetic Scaffolds Increased Resveratrol Biosynthesis in Engineered Yeast Cells. J. Biotechnol. 157, 258-260. doi:10.1016/j.jbiotec.2011.11.003

Watts, K. T., Lee, P. C., and Schmidt-Dannert, C. (2006). Biosynthesis of Plantspecific Stilbene Polyketides in Metabolically Engineered Escherichia coli. BMC Biotechnol. 6, 22. doi:10.1186/1472-6750-6-22
Wu, J., Du, G., Chen, J., and Zhou, J. (2015). Enhancing Flavonoid Production by Systematically Tuning the central Metabolic Pathways Based on a CRISPR Interference System in Escherichia coli. Sci. Rep. 5, 13477. doi:10.1038/ srep 13477

Wu, J., Liu, P., Fan, Y., Bao, H., Du, G., Zhou, J., et al. (2013). Multivariate Modular Metabolic Engineering of Escherichia coli to Produce Resveratrol from L-Tyrosine. J. Biotechnol. 167, 404-411. doi:10.1016/ j.jbiotec.2013.07.030

Wu, J., Yu, O., Du, G., Zhou, J., and Chen, J. (2014). Fine-tuning of the Fatty Acid Pathway by Synthetic Antisense RNA for Enhanced (2S)-Naringenin Production from L-Tyrosine in Escherichia coli. Appl. Environ. Microbiol. 80, 7283-7292. doi:10.1128/AEM.02411-14

Wu, J., Zhou, P., Zhang, X., and Dong, M. (2017). Efficient De Novo Synthesis of Resveratrol by Metabolically Engineered Escherichia coli. J. Ind. Microbiol. Biotechnol. 44, 1083-1095. doi:10.1007/s10295-017-1937-9

Xiong, D., Lu, S., Wu, J., Liang, C., Wang, W., Wang, W., et al. (2017). Improving Key Enzyme Activity in Phenylpropanoid Pathway with a Designed Biosensor. Metab. Eng. 40, 115-123. doi:10.1016/j.ymben.2017.01.006

Yang, H., Zhang, X., Liu, Y., Liu, L., Li, J., Du, G., et al. (2021). Synthetic BiologyDriven Microbial Production of Folates: Advances and Perspectives. Bioresour. Technol. 324, 124624. doi:10.1016/j.biortech.2020.124624

Yang, Y., Lin, Y., Li, L., Linhardt, R. J., and Yan, Y. (2015). Regulating Malonyl-CoA Metabolism via Synthetic Antisense RNAs for Enhanced Biosynthesis of Natural Products. Metab. Eng. 29, 217-226. doi:10.1016/j.ymben.2015.03.018

Yuan, S.-F., Yi, X., Johnston, T. G., and Alper, H. S. (2020). De Novo resveratrol Production through Modular Engineering of an Escherichia ColiSaccharomyces cerevisiae Co-culture. Microb. Cel Fact 19, 143. doi:10.1186/ s12934-020-01401-5

Zaffaroni, N., and Beretta, G. L. (2021). Resveratrol and Prostate Cancer: The Power of Phytochemicals. Cmc 28, 4845-4862. doi:10.2174/ 0929867328666201228124038

Zha, W., Rubin-Pitel, S. B., Shao, Z., and Zhao, H. (2009). Improving Cellular Malonyl-CoA Level in Escherichia coli via Metabolic Engineering. Metab. Eng. 11, 192-198. doi:10.1016/j.ymben.2009.01.005

Zhang, E., Guo, X., Meng, Z., Wang, J., Sun, J., Yao, X., et al. (2015). Construction, Expression, and Characterization of Arabidopsis thaliana 4CL and Arachis hypogaea RS Fusion Gene 4CL:RS in Escherichia coli. World J. Microbiol. Biotechnol. 31, 1379-1385. doi:10.1007/s11274-015-1889-z

Zhang, H., and Stephanopoulos, G. (2013). Engineering E. coli for Caffeic Acid Biosynthesis from Renewable Sugars. Appl. Microbiol. Biotechnol. 97, 3333-3341. doi:10.1007/s00253-012-4544-8

Zhou, H.-B., Yan, Y., Sun, Y. N., and Zhu, J. R. (2003). Resveratrol Induces Apoptosis in Human Esophageal Carcinoma Cells. Wjg 9, 408-411. doi:10.3748/wjg.v9.i3.408

Zhou, K., Qiao, K., Edgar, S., and Stephanopoulos, G. (2015). Distributing a Metabolic Pathway Among a Microbial Consortium Enhances Production of Natural Products. Nat. Biotechnol. 33, 377-383. doi:10.1038/nbt.3095

Zulueta, A., Caretti, A., Signorelli, P., and Ghidoni, R. (2015). Resveratrol: A Potential Challenger against Gastric Cancer. Wjg 21, 10636-10643. doi:10.3748/wjg.v21.i37.10636

Conflict of Interest: The authors declare that the research was conducted in the absence of any commercial or financial relationships that could be construed as a potential conflict of interest.

Publisher's Note: All claims expressed in this article are solely those of the authors and do not necessarily represent those of their affiliated organizations, or those of the publisher, the editors and the reviewers. Any product that may be evaluated in this article, or claim that may be made by its manufacturer, is not guaranteed or endorsed by the publisher.

Copyright () 2022 Feng, Chen, Ye, Liao, Wang, Song and Qiao. This is an openaccess article distributed under the terms of the Creative Commons Attribution License (CC BY). The use, distribution or reproduction in other forums is permitted, provided the original author $(s)$ and the copyright owner $(s)$ are credited and that the original publication in this journal is cited, in accordance with accepted academic practice. No use, distribution or reproduction is permitted which does not comply with these terms. 